\title{
PREDICTION MODEL TO REDUCE ENERGY CONSUMPTION OF MOSQUE BUILDINGS: REVIEW PAPER
}

\section{EMAD AMEEN ALHARBI \& ROSLI MOHAMAD ZIN}

School of Civil Engineering, Faculty of Engineering UniversitiTeknology Malaysia, Skudai, Johor Bahru, Malaysia \begin{abstract}
Recently, the number of mosques dramatically increased due to dramatic increase of urban and populations. About 3.6 million of mosques are spreading around the world and the number of mosques is expected to increase to 3.85 million in year 2019, which consume huge amount of energy. However, comparing to other building types, the searching in terms of enhancing sustainability and reduce energy consumption is considered as a new topic. In addition, only on the last 20 years the researchers have highlighted the issues that confronted the mosque building. In this paper a literature review is presented on previous 20 years of researches which aims to investigate the current situation of researches on predicting the energy consumption of mosques. Moreover, to investigate the issues confronting the sustainability achievement and energy efficiency criteria of mosques as well as provides recommendation for future studies. Although there is such a high annual energy used per capita, the results show clear gab and lack of researches in many aspects in regard with mosques. Accordingly, this emphasizes the need for adopting new policies from government and applying new strategies to decrease energy consumption by applying energy efficiency criteria. The conclusion summarized several recommendations for future studies.
\end{abstract}

KEYWORDS: Energy Consumption, Energy Efficiency, Prediction Model, Sustainable Environment, Mosque Building

Received: Jun 08, 2020; Accepted: Jun 28, 2020; Published: Sep 14, 2020; Paper Id.: IJMPERDJUN20201209

\section{INTRODUCTION}

The Mosque is a place for worship and religious activities, place for learning, the place for charitable activities, detention and rehabilitation center. Muslim community is accounted to be about quarter of the world population, with numerous existed mosques that spreading all around the world (Azmi\&Kandar, 2019). Mosque is considered as an integral part for any communities with Muslim majorities as well other countries that have Muslim populations. Thus, Mosque building carries a great social and spiritual place in the lives of the Muslims to worship God. Mosque represents a place with great importance and unique function that Muslims can come daily together for five intermittent prayer periods with duration between 45 and 60 min each.Hence, a mosque should be designed properly to provide privacy, comfort and calm in the worship area so that worshippers can leave with the feeling of a peace and tranquility (Alabdullatief et al., 2016; Abdul-Matin, 2010).

Recently, the number of mosques dramatically increased due to dramatic increase of urban and populations. About 3.6 million of mosques are spreading around the world in 2014 which consume huge amount of energy due to inefficient use of HVAC systems. Additionally, the percentage of growth is estimated to be $1.3 \%$ per year and the number of mosques is expected to increase to be about 3.85 million in year 2019 (Deloitte et al., 2015; Al-Tamimi \& Qahtan, 2018). 


\subsection{Objectives of the Paper}

The aim of this paper is mainly focuses on achieving the following two objectives:

- To investigate the current situation of researches on predicting the energy consumption of mosques.

- To investigate the issues confronting the mosques in regard with energy consumption and environmental sustainability as well as provide recommendations for further future studies.

\section{LITERATURE REVIEW}

\subsection{Energy Consumption in Mosque Buildings}

Comparing to other types of buildings, Mosque is considered as the most temporarily and frequently used building. Unfortunately they consume a huge amount of energy due to several reasons such: improper and poorly design, lack of studies, and improperly operated. However, the potential for energy conservation is significant (Alsaeah 2013; Budaiwi et al., 2013). There is a clear gab and lack of case studies in terms of enhancing sustainability and reduce energy consumption and how mosques should be designed properly. In this respect, comparing to other buildings types, the searching in terms of enhancing sustainability and reduce energy consumption is considered as a new topic. In addition, only on the last 20 years the researchers have highlighted the issues that confronted the mosques buildings (Alabdullatief\& Omer, 2017).

While there are numerous previous researches in regard with mosque building, some of the crucial issues need for further investigation such as: energy efficiency criteria, sustainable designs, low energy, indoor thermal performance, passive strategies, and guidelines of design alternatives (Azmi\&Kandar, 2019; Alashaab\&Alamery 2018; Alabdullatief et al. 2016; Al-Shaalan 2017). However, these mosques need to be carefully designed in regard with energy requirements and thermal performance, because these issues have not been adequately addressed (Al-Tamimi\&Qahtan, 2018). As a result, the most common problem in the mosques is the energy waste, which is related to the design and unclear design alternatives and design parameters that important for the overall design process. In addition, Most studies conclude that the thermal and air-conditioned play a vital role in increasing the energy consumption of mosques (Budaiwi et al., 2013; Alabdullatief et al., 2016; Alabdullatief \& Omer, 2017; Alsaeah, 2013; Azmi\&Kandar, 2019; Mushtaha\&Helmy, 2016; Alajmi, 2010; Kamar, 2015; Al-Tamimi \& Qahtan, 2018; Alashaab \& Alamery, 2018; Ibrahim et al., 2014). Figure 1 represents a summary of Mosque general problems.

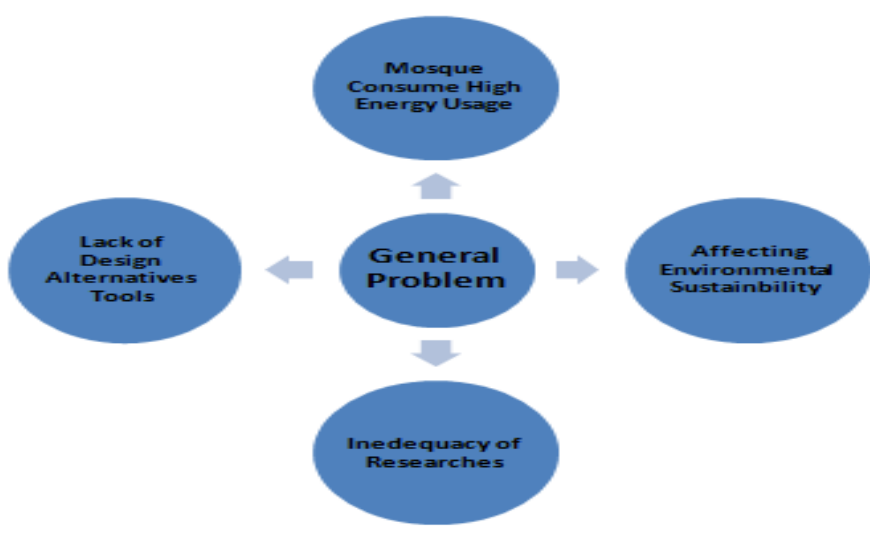

Figure 1 Summary of Mosque General Problems. 


\subsection{Energy Consumption of Mosques in Saudi Arabia and Current Situation}

In Saudi Arabia the number of mosques that built by the government has significantly increased from (55,266 in 2008 to reach more than 102,580 in 2015). The reason is the cities in Saudi Arabia have witnessed an increase in urbanization and architecture (Al-Howaimel, 2013; MIADG, 2017). However, many other mosques are under private management, indicating that the number of mosques dramatically increased by approximately $58.6 \%$ within 7 years between 2008 and 2015 with an annual average of $12 \%$. All these thousands of Mosques spreading across the Kingdom of Saudi Arabia, consuming nearly 3 Terawatt-Hours of electrical energy, $70 \%$ of which is due to the use of mostly inefficient HVAC systems (Al-Tamimi \& Qahtan, 2018). Additionally, Mosques consume large amounts of water, as prayer requires ablution; the act of washing exposed body parts in preparation for the prayers. It is estimated that nearly 7 billion gallons (26 million [M.sup.3]) and the water usage in such a severely water stressed country, coupled with the fact that electricity consumption has been steadily increasing by nearly $8 \%$ annually for the past 10 years, makes it imperative to adopt innovative ideas not only to use water effectively, but also to find ways to control power demand growth rate (Budaiwi et al., 2013).

Mosques are highly dependent on A/C systems to achieve thermal comfort, because of the harsh climatic conditions in Saudi Arabia. Additionally, Mosques are often improperly operated and not normally insulated which resulting in both unnecessary of energy consumption and uncomforted of indoor conditions. The analyzing of electricity bills and the average of monthly distribution of energy used in five representative mosques that located in Eastern side of Saudi Arabia indicated that $(\mathrm{A} / \mathrm{C})$ air is the highest energy consumer for electricity which was estimated to be about $73 \%$ and for ceiling fans and lighting were estimated to be $22 \%$ and $5 \%$ respectively (Al-Homoud et al., 2005). This is due to the high dependency on A/C systems and due to harsh climatic weather in Saudi Arabia especially in summer months. However, the average energy used per capita for a typical mosque is estimated to be approximately $182.0 \mathrm{kWh} /(\mathrm{m} 2 \mathrm{yr})$. This high annual energy used per capita have emphasizes the need for adopting new polices from government and applying new strategies for energy conservation for mosque buildings. Figure 2 represents a comparison of energy consumption usage between mosques and some other public sectors in 2013 (Alsaeah, 2013; Alabdullatief et al., 2016).

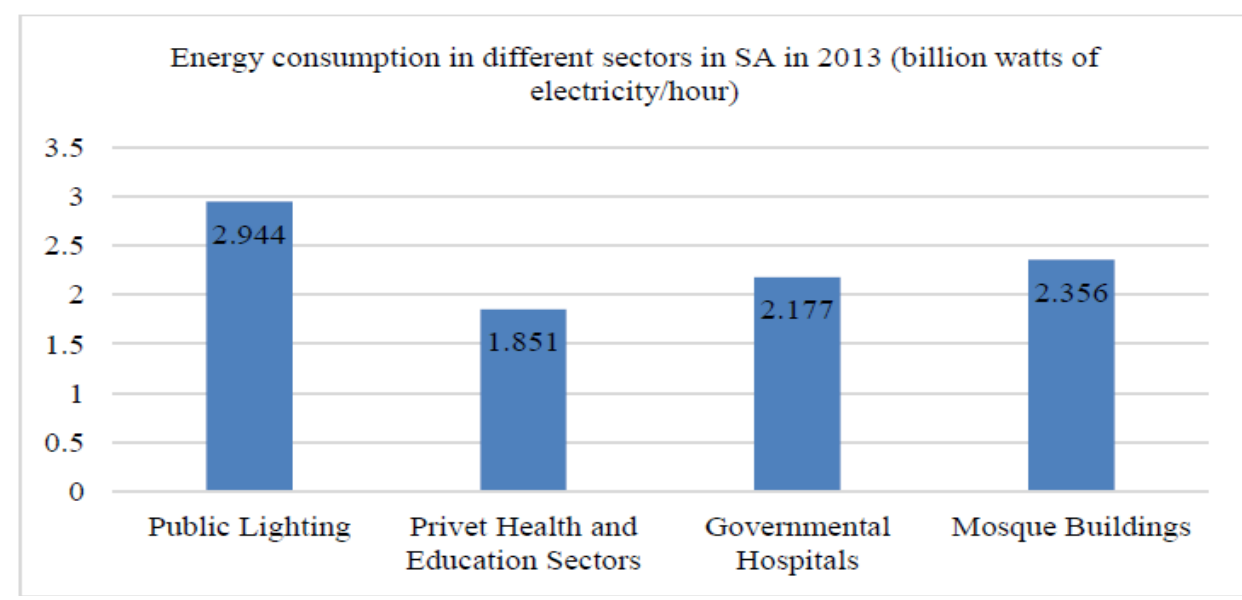

Figure 2: Mosques Are Consumed Energy More Than Hospitals In Saudi Arabia (Alsaeah, 2013). 


\section{METHODOLOGY}

This paper is mainly aims to conduct a literature review for the previous related studies in the latest energy consumption researches trends in regard withmosque buildings by obtaining numerous researches and articles which were sorted and limited to articles that have been published from the year of 2000 till 2020. During this time essential changes have been occurred in the developing of mosque designing, constructing, and operating. Additionally, while there are essential computational and building simulations tools have been established before this period, a significant increase world widely in the progress of related simulation materials andprediction models. In addition, there is an increased attention by researchers and academics to expand and improve the accuracy, capacity, and speed of prediction tools.

Therefore, the conducted literature review has investigated different websites and domains such as Science direct, Springer, and Web of sciences, proQuest, Scopus, and Google Scholars databases were used for searching in both stages. Scholarly journal articles and conference papers published in English were selected for the review, which help to obtain related thesis and articles in the focused field of energy consumption in Mosques. The methodology used few key words that related with mosque such as: "energy consumption”, energy efficiency", "energy conservation”, “ sustainability”, "green buildings”, “ thermal performance", "indoor thermal comfort", and "prediction model". After initial filtering, 44 relevant articles were found and considered valid for further analysis. However, this study is solely focuses on reviewing the relevant articles of predicting the energy consumption in mosques through specific literature review and it is not on complete population of articles in regard with the topic

\section{RESULTS}

\subsection{Descriptions of Related Studies}

It is important to mention that despite there are number of research efforts in regards with energy consumption of mosque buildings, the conducted literature review found that there is still a lack on review studies that cover the energy consumption at Mosque buildings. However, this paper study is the first to investigate the current and related works in regard with the scope of energy consumption at mosques.

In addition, as per the results of conducted literature review in related works of energy consumption in Mosques from the year 2000 till 2020, numerous studies came up with various solution techniques and strategies methods to develop the thermal system, decrease the energy consumption, and evaluate the environmental condition in Mosque buildings around the world such as: (Mushtaha\&Helmy 2016; Al-Homoud et al., 2005; Sezer\&Kaymaz, 2016; ElShennawy\& Abdallah, 2017; Azmi\&Kandar, 2019; Abdou et al., 2005; Al-Tamimi \& Qahtan, 2018; Bakri et al., 2018; Mokhtar, 2015; Nordin\&Misni, 2018). These studies proposed different strategies and architectural improvements in mosque buildings to reduce the energy consumption such as PV systems, roof options, glazing techniques, building forms, passive and envelope designs, conceptual frameworks, facilities management, and guidelines for design.

Therefore, some other studies proposed different design strategies after the adaptation of simulation software tools to examine different strategies for the thermal load systems such as, (Toumal \& Ouahrani, 2016; Al-Shalaan et al., 2017; Budaiwi et al., 2013; Laghmich et al. 2018; Abdullatief\& Omer, 2017; Shohan 2015). These studies have tested different alternatives and considered different simulation case studies to find the best appropriate solutions for mosques. 
On the other hand, and as per the scope of this paper, few researches have been found that considered prediction and simulation models in their evaluations to reduce energy consumption and enhance thermal performance such as, (Alajmi, 2010; Ibrahim et al., 2014; Hussin et al., 2015; Hussin et al., 2018; Calis\& Kuru 2015; Kamar et al., 2015; Alashaab \& Alamery 2018; Samiuddin \& Budaiwi, 2018; Atmaca \& Gedik 2019). These studies are mainly focused on evaluating the indoor thermal comfort and assess the level of occupants comfort inside the mosque by applying PMV and PPD methods.

Nevertheless, there are number of limitations have been observed in this review from previous studies with providing some recommendations and future aspects. The literature review shows improvement in the materials used for energy efficiency development during the years, which is a corresponding to the recent advanced technologies that can help in evaluating and reducing energy consumption of building more accurately. Examples of recent technologies that used and approved its abilities to reduce energy consumption, such as: BIM software, Simulation tools, and Predictions models.

\subsection{Implementation of Prediction Models for Mosque Buildings}

Prediction models are considered as a new tool in latest few years to calculate and predict the energy consumption in construction buildings. Beside have numerous benefits of prediction models in estimating the energy consumption in all building stages, however, still there are several drawbacks and challenges need further investigation such as not user friendly, level of accuracy, and need previous knowledge about it (De Boeck et al., 2015; Amasyali\& El-Gohary, 2018). As per the literature reviews of previous researches and studies, only very few research been conducted to predict the energy consumption for Mosque buildings around the world such as Kuwait, Turkey, Malaysia, Iraq, Qatar, Saudi Arabia, and UEA. However, all these researches aimed to improve the indoor thermal comfort inside mosques for existed mosques. Additionally, these researches have been conducted by the researchers such as (Hussin et al., 2015; Calis and Kuru 2015; Kamar 2015; Alashaab\&Alamery 2018; Samiuddin\&Budaiwi, 2018; Atmacan \& Gedik 2019).

Most of these conducted studies have applied (PMV) prediction of mean vote method in their research as well as the use of Fanger's model, (CFD) computational fluid dynamic, and (PPD) predicted percentage of dissatisfied. Accordingly, PMV is confirmed by numerous studies as an accurate tool to predict the occupant perception in several climate cases. Fanger's method is considered as a theoretical analysis to assess the human heat and to assess buildings with intermittent occupancy. In addition, this method may not perform the same in other building types such as residential and commercial facilities. However, the perception of occupants and the indoor thermal comfort need to be more investigated (Calis et al., 2015).Moreover, coupling between environment simulation and building energy have approved its sufficient results in evaluating the indoor environment and for cooling/heating calculation. The use of CFD in estimating the impact of distribution of room air temperature is a good option. Therefore, these couplings of methods have been implemented and become available and mature in several commercials software, such as DesignBuilder.

For example the study of (Alajmi, 2010) investigated the level of prayers comfort and the indoor thermal system inside six mosques during the summer in the state of Kuwait. The method was to present a statistical data and analysis of prayer thermal comfort sensations. In addition to that a questionnaire was applied to collect the subjective data. The results of the study found that the temperature of neutral prayers (Tn) is about 26.1_C, whereas the result for PMV was about 23.3_C. The level of existing scales to measure the thermal comfort, found to be not very applicable for the typology of Mosque. 
The objectives of the study of (Ibrahim et al., 2014) are to investigate and test the thermal comfort conditions in Mosque case study at Kota, Sarawak. They proposed the Corrected Effective Temperature (CET) to analyze the collected data. The result shows a significant enhancement in the performance of indoor thermal comfort inside the mosque case study.

The study of (Hussein et al., 2015) conducted a study to investigate the reliability of PMV model in predicting the indoor thermal system during various daily prayers in a Mosque at Penang, Malaysia. In order to investigate the reliability, they conducted a field study between the estimated PMV and the actual climate measured resulted from the recorded sensations of occupant comfort. Fanger equation was applied in the study and the results show even most of worshippers (felt neural) and accepted their thermal environment, the PMV value shows (slightly warm) which mean discomfort. The comfort temperature was ranged between (27.0_C and 31.4_C) and the thermal acceptance corresponds to OPT was ranged between (+0.5 to -0.5). The finding of study confirmed that the PMV model is not appropriately suitable to predict the indoor thermal system during various daily praying especially at hot and humid environment weathers.

The study of (Calis\& Kuru 2015) conducted to assess the thermal comfort by monitoring the indoor environmental conditions of a case study of historic Mosque located hot-humid climatic region in Turkey. Similarly, the study highlighted the differences between the actual calculated values and the occupant perceived satisfaction and evaluated the amount of (PMV and PPD) by using the international ASHRAE standard 55-2010. The two researchers conducted a questionnaire based on the seven-point scale of Fanger's method in order to investigate the occupant's preferences and understand the thermal sensation. Results of PMV was about (1.04) which mean the occupants feel slightly warm and the value of AMV was about (-0.58) which indicates the mean of slightly cool. However, during the two months of August and September the values of operative temperature were found within (27.0 and 31.0). The study recommended further future researches in estimating the perception of occupants especially in the summer time.

The study by the group of (Kamar et al., 2015) applied the use of (CFD) computational fluid dynamic index method in Malaysia's Mosques. The main objectives were to test the potential effect of installing the exhaust fans and to predict the distribution of temperature and the airflow within the mosque buildings. Similarly, the study intended to propose a strategy that used to optimize the indoor thermal system in the mosques. For the period of one year the study carried out a field measurement to estimate the air temperature, velocity of airflow, and temperature of mean radiant. Results show significant improvement in the thermal system by successfully installing a one meter diameter for the exhaust fan in the south-side wall of the mosque and the height from the floor was six meter. This implementation has the potential to reduce the value of PMV by approximately $75-95 \%$, and for the PPD value was approximately 87-91\%.

The study of (Hussin et al.2018) in Mosques at Penang, Malaysia, has the aim is to investigate the current thermal comfort performance of air-conditioned in a large-space Mosques which the floor area was about 2,920 m2 as well as the airconditioned system was irregular and discontinues operation. Moreover, they tested number of methodologies to improve the cooling system and thermal comfort by employing (PMV) predicted mean vote. The results of this study were within the ASHRAE Standard 55 and the sensation of the predicted thermal under (PMV) model have been achieved successfully within the range of comfort zone which is between $(-0.5,+0.5)$. Additionally, the study found that the energy consumption can be reduced when maintaining the level of thermal comfort of occupants. 
Alashaab\&Alamery (2018) used mixed of methods such as simulation software (Ansys -Fluent v.18), PMV to predict the thermal comfort, (PPD) predicted the percentage of dissatisfied, and (CFD) computational fluid dynamics. One objective from the study was to improve and evaluate the thermal comfort of the mosques occupants at Friday prayers at hot-dry climate of Mosque in Baghdad, Iraq. The study conducted at the time of Friday prayer, and divided the simulated case studies into 4 million mesh element. The study applied the standard of ASHRAE-55 and the use of PMV and PPD models in order to assess the thermal comfort. K-e (RNG) turbulent was found to be the best model in terms of flow distribution, and the temperature was estimated to be approximately 0.4_C, which was indicated lower than the original state. In addition, the result of the redistribution strategy of adaptive devices was found to be successfully in obtaining the best thermal comfort level.

On the other hand, only one study in Saudi Arabia that implemented the use of prediction PMV model by the study of (Samuddin\&Budaiwi, 2018). They applied a combination of different method by calculating the (ADP) Air diffusion performance with the use of Fanger's PMV methods to assess the thermal comfort in high occupancy spaces inside mosques in Saudi. Subsequently, they employed (CFD) computational fluid dynamics techniques and EnergyPlus software to test three schemes of air distribution in four terminal velocities diffuser. Results show different variation between the air-diffusion distribution scheme and the velocity of terminal diffuser. The results of overcooled spaces of PMV indicted 0.66 or below, whereas, the PMV uniformity was entirely dependent on the air-diffuser performance which indicated to be low.

Although there is only one research study that considered the use of prediction of PMV in the evaluation for mosque building in Saudi Arabia by (Samuddin\&Budaiwi, 2018), Prediction models in Saudi Arabia are still promising and considered as new tools for estimating the energy consumption and optimize the indoor thermal system inside mosques and have been applied successfully in numerous studies and in different buildings types such as residential, commercial, and office building (Alshibani\&Alshamrani, 2017).

\section{DISCUSSIONS AND FUTURE TRENDS}

The observation from the results of literature review for previous researches efforts indicates that there are numbers of limitations have been assessed, and some research areas require more attention as well as future directions and recommendations are provided. However, these limitations are summarized and categorized into four main sections.

- Implementation of Prediction models for mosque buildings.

- Lack of design decision tools and prediction models implementation at early design stage.

\subsection{Implementation of Prediction Models for Mosque Buildings}

As result from above previous studies, it is to be mention that there are several limitations in studies in regards with prediction the air temperature inside mosque buildings and the use different techniques such as PMV, PPD, and CFD have been discovered. As a result, there are six studies have applied the use of prediction models in their evaluation for thermal cooling load system. This review paper highlighted the need to fill up the gap of lack researches that consider mosques in their evaluation especially, the superiority of using prediction models. These limitations can be used as a baseline for further improvement for researchers and for upcoming studies especially for Mosques and can be mainly summarized in Table1. 
Table 1 show in the context of Saudi Arabia and as per the results of literature review, which show a clear lack of reaches that implement the use of prediction models in estimating the energy consumption, occupants perception, and the indoor thermal comfort. The literature found one study by (Samuddin \& Budaiwi, 2018), which was mainly aims to improve the level of indoor comfortable environment by adopting the use of (ADP) air diffusion performance, (CFD) computational fluid dynamic, and estimate the level of PMV value that resulted within the limit. Although there is only one research study that considered the use of prediction of PMV in the evaluation for mosque building in Saudi Arabia by (Samuddin\&Budaiwi, 2018), Prediction models in Saudi Arabia are still promising and considered as new tools for predicting the energy consumption and the energy cost which have been applied successfully in numerous studies and in different buildings types such as residential, commercial, and office building.(Alshibani\&Alshamrani, 2017).

These limitations which were described previously in (Table.1) can be used as a baseline for further studies and improvement in future, especially for Mosques. However, these limitations can be mainly summarized as shown below:

- The existing scales may not be applicable for the mosque typology and founding should consider when design mosque

- Some studies confirmed that the PMV model is not appropriately suitable to predict the indoor thermal system during various daily praying especially at hot and humid environment weathers.

- Several PMV results show that the comfort level for occupants is not achieved due to different factors in many cases

- There is still a need for large improvement in thermal comfort inside other sections in mosque building.

- Thermal comfort designs are only relies on nature of air distribution system.

- Space is thermally comfortable only when the thermal uniformity is sufficient and the PMV value is within defined limits

- CFD analysis achieving air temperature uniformity and air speed for space is not possible, and relies on several factors As a conclusion from previous literature review on occupants perception prediction, further researches, need to be integrated towards various aspects such as coupling the energy simulation tools with indoor environment methods, coupling between the distribution detailed model with airflow velocity, and an effort to estimate the whole building performance. Computation and simulation methods should be connected to handle more complexity designs and to provide a complete guide for designers. In addition, the results show the estimation of occupant behaviors factor and their level of comfort are difficult and the accuracy of results is a challenging task. These limitations bring the uncertainty in prediction occupant perception. However, as a recommendation for future researches, there is a need for estimating the perception of occupants especially in the summer time

Table 1: Summary of Related Works for Prediction Models in Mosque Buildings.

\begin{tabular}{|c|c|c|c|c|}
\hline Author \& Year & $\begin{array}{l}\text { Building } \\
\text { Type }\end{array}$ & $\begin{array}{l}\text { Prediction } \\
\text { Model }\end{array}$ & Other Methods & Limitations \\
\hline $\begin{array}{l}\text { Alajmi } \\
\text { ( 2010) }\end{array}$ & Mosque & PMV & $\begin{array}{l}\text { Field study in six } \\
\text { mosques } \\
\text { Analysis of } 140 \\
\text { subjects } \\
\text { Questionnaires to }\end{array}$ & $\begin{array}{l}\text { 1-Values results are about } 2.8-\mathrm{C} \text { which is } \\
\text { higher than predicted by PMV model. } \\
\text { 2-Only contribution related design codes for } \\
\text { Kuwait } \\
\text { 3-Findings are consider when designing air- }\end{array}$ \\
\hline
\end{tabular}




\begin{tabular}{|c|c|c|c|c|}
\hline & & & collect data. & conditioning for mosque buildings \\
\hline Hussin et al (2014) & Mosque & PMV & $\begin{array}{l}\text { Field study } \\
\text { Fanger equations to } \\
\text { calculate PMV. } \\
\text { survey of } 330 \text { to } \\
\text { calculate the } \\
\text { (AMV).Actual Mean } \\
\text { Vote }\end{array}$ & $\begin{array}{l}\text { 1-Not all worshippers accepted their thermal } \\
\text { environment (felt neutral) even PMV } \\
\text { indicates discomfort (slightly warm). } \\
\text { 2-findings confirm PMV model is not } \\
\text { appropriate to predict thermal comfort in } \\
\text { A/C of mosques during various daily prayer } \\
\text { modes for hot/ humid environment }\end{array}$ \\
\hline $\begin{array}{c}\text { Calis } \\
\text { \& Kuru (2015) }\end{array}$ & Mosque & $\begin{array}{l}\text { PMV } \\
\text { (PPD) }\end{array}$ & $\begin{array}{l}\text { Fanger'sof seven- } \\
\text { point scale } \\
\text { Questionnaire } \\
\text { Compare of calculated } \\
\text { and perceived } \\
\text { satisfied of occupants. }\end{array}$ & $\begin{array}{l}\text { 1-PMV found the environment is slightly } \\
\text { warm (PMV=1.04). whereas AMV value is } \\
(-0.58) \text { mean slightly cool } \\
\text { 2- Temperature found between }(27.0-31.00 \\
\text { for August and September, in addition to, } \\
\text { the need of comparison between calculated } \\
\text { and perceived occupants. } \\
\text { 3-future studies recommended for perception } \\
\text { of occupants during summer season }\end{array}$ \\
\hline (Kamar et al (2015) & Mosque & $\begin{array}{l}\text { PMV } \\
\text { (PPD) }\end{array}$ & $\begin{array}{l}\text { (CFD) for airflow } \\
\text { prediction. } \\
\text { Test the effect of } \\
\text { install exhaust fans }\end{array}$ & $\begin{array}{l}\text { 1-Only examined the install of exhaust fans } \\
\text { 2-height of } 6 \text { m from the floor has potential } \\
\text { of reducing PMV by 75-95\% and the PPD } \\
\text { index by } 87-91 \% \text { could be improved. 3-The } \\
\text { need for vast improvement in the thermal } \\
\text { comfort inside other sections in mosque } \\
\text { building. }\end{array}$ \\
\hline Hussin et al.(2018) & Mosque & PMV & $\begin{array}{l}\text { Case study in large } \\
\text { mosque } \\
\text { usage of cooling } \\
\text { systems such as } \\
\text { Air conditioning } \\
\text { system. }\end{array}$ & $\begin{array}{l}\text { 1-Not all the Result of indoor thermal } \\
\text { environment within the range of ASHRAE } \\
\text { Standard 55. } \\
\text { 2-energy consumption reducing while } \\
\text { maintains thermal comfort of occupants. } \\
\text { 3-hard to predict occupants level of comfort } \\
\text { due to fluctuation of occupancy level }\end{array}$ \\
\hline $\begin{array}{l}\text { Alashaab\&Alamery } \\
\text { (2018) }\end{array}$ & Mosque & PMV PPD & $\begin{array}{l}\text { mixed methods such } \\
\text { as simulation software } \\
\text { (Ansys -Fluent v.18), } \\
\text { (CFD) computational } \\
\text { dynamics, } \\
\text { Divisions simulated } \\
\text { case studies into four } \\
\text { millions mesh element }\end{array}$ & $\begin{array}{l}\text { 1-was to improve thermal comfort inside } \\
\text { mosque with full occupantOnly on hottest } \\
\text { days of the years and only in July month. } \\
\text { 2-several simulations to re-distribute and } \\
\text { obtain the best improvement rate } \\
\text { 3-the result of improved PMV was }(4.43 \%) \text {, } \\
\text { and for PPD was (5.96\%) which considered } \\
\text { lowers than the original state }\end{array}$ \\
\hline $\begin{array}{l}\text { Samiuddin\&Budaiwi, } \\
\text { (2018) }\end{array}$ & Mosque & PMV & $\begin{array}{l}\text { (ADP) Air diffusion } \\
\text { performance Fanger's } \\
\text { model to assess } \\
\text { thermal } \\
\text { Energy Plus } \\
\text { simulation software } \\
\text { (CFD) computational } \\
\text { dynamics }\end{array}$ & $\begin{array}{l}\text { 1-Thermal comfort designs are only relies on } \\
\text { nature of air distribution system } \\
\text { 2-Space is thermally comfortable only when } \\
\text { the thermal uniformity is sufficient and the } \\
\text { PMV value is within defined limits } \\
\text { 3-CFD analysis achieving air temperature } \\
\text { uniformity and air speed for space is not } \\
\text { possible, and relies on several factors }\end{array}$ \\
\hline
\end{tabular}

\subsection{Lack of Design Decision Tools and Prediction Models Implementation at Early Design Stage}

This paper study is a part of current research to develop a prediction tool that can assist designers at the early stage of design mosques in reducing the energy consumption. However, this is due to the fact that the percentage of mosque growth is estimated to be $1.3 \%$ per year and the numbers of mosques are expected to increase to be about 3.85 million in 2019 (Deloitte 
et al., 2015; Al-Tamimi\&Qahtan, 2018). In line with the growing population of Muslims, there is a demand for establishing new mosques all around the globe. In addition, the increasing claim towards sustainable buildings is generally due to the global warming, which becomes a significant issue. Although there are recently some polices were adopted from countries such as Indonesia, Qatar, Jordan, Morocco to promote sustainable and green mosques and friendly design solution, most of these resolution still at early planning level and most of these decisions are not focusing to find new strategies, especially for older designed buildings which approved to be costly (Azmi\&Kandar, 2019).

Therefore, the energy efficiency of buildings has not been given serious attention in Saudi Arabia compared to other countries (Alshibani\&Alshumrani, 2017). In addition, fixing the deficiencies in the existing architectural design of constructed facilities is costly and time-consuming. From an architectural design point of view, the literature concluded that several common issues in the design of buildings are the main cause of high energy consumption in the Saudi building sector (Alshibani\&Alshamrani, 2017). It also estimated that proper architectural design solutions can save around 250 million barrels of oil equivalent over a five-year period. As a result, architectural designers use a few design solutions and ignore many others. However, some architects who design buildings with different techniques and fancy glazing facades need to consider the cost of additional HVAC load in their designs (Alsaggaf et al., 2020).

\subsection{Lack of Design Decision Tools to Support Architects and Designers at Early Stage}

Nevertheless, there is a need for tools and techniques to help architects, along with other professionals and stakeholders in the building industry to make wisely decisions and informed choices in pre-design stage. In addition, architects are usually suffer from limited knowledge of energy modeling and outsource of substantial cost and often performed in late design stages, when there is not much scope left for incorporating corrective changes in design. Consequently, there is limited available design decision supported tools to quickly assess and evaluate the energy performance of multiple design options in early stage. Hence, there is a need to explore other techniques that can be adapted for building energy prediction and optimization for this purpose. In addition, Architects and designers do not have enough knowledge for using the simulation tools. They are usually incapable of thoroughly assessing option and their respective energy consumption implications, due to the lack of knowledge for energy efficiency (Basbagill et al., 2013).

\subsection{Lack of Energy Efficiency Design Implementation at Early Stage}

Buildings are responsible for a tremendous amount of energy consumption due in part to their long lifetimes and continuous operation. Efficient design is critical, especially at the early stages, as a result of poor decisions made early become difficult or impossible to correct. In addition in terms of energy efficiency at earlier stage, the energy-efficiency design has become a hot topic and has received unanimous attention from governments, developers, owners, and researchers (Li et al., 2019). Accordingly, buildings must be designed with more effective and efficient energy use to mitigate further increases in energy consumption and CO2 emissions (Tran et al., 2019).

Therefore, the energy-efficient design concept intervention is essential due to the scarcity of natural resources, and unfortunately, the issues of energy consumption, energy performance, and energy efficiency of Mosques in particular are not generally given serious consideration in Saudi Arabia (Al-Tamimi\&Qahtan, 2018). Therefore, it is also necessary to identify the key design parameters for energy efficiency performance that have a significant and direct impact on the annual energy 
consumption of the buildings (Lao and Peng, 2016; Elbeltagi et al., 2017).

\subsection{Lack of Research Implementation in the Early Design Stage}

The early stage of design is considered the most critical stage to make decisions on design alternatives that impact energy performance (Alsagaf et al., 2020). In addition, the early stage of design have a great impact on the energy performance, however, fixing the deficiencies in the existing architectural design of constructed facilities is costly and time-consuming (Alshibani \& Alshumrani, 2017).

Several researches have confirmed the notion that it is widely believed that over the buildings projects lifecycle, design stage is the most promising phase in terms of energy efficiency design as decisions here affect about 60 to $70 \%$ of the lifecycle costs of construction and operation (Kim et al., 2011). Thus, numerous researches have approved the requirement for reducing energy consumption, which appears to be the most important aspect of the early buildings design stage. However, it is often challenging to estimate the energy consumption of a building in early design stage, due to the high level of subjectivity by architects and engineers in this stage (Alsaggaf et al., 2020).

In reality, many design decisions affecting energy requirement of buildings are taken at early stage, when adequate information to support such decisions is not available due to lack of tools (Batish\& Agrawal, 2019). The energy efficiency design of building can assist architectures in achieving the most significant of energy saving. However, over $40 \%$ of the potential of energy saving comes from the pre-construction phase stage and the performance of building is significantly affected by the decisions at early design stage ( $\mathrm{Li}$ et al., 2019). The concept of design stage is particularly important in designing a sustainable construction and buildings performance, because of ability of selecting the best design after the choosing of best assessment tools and raw materials (Kim \& Ham, 2012). It has been widely recognized that, design decisionthat made in the pre-design stage has major effect on the final performance and costs of building costs (Østergård et al., 2017).

\subsection{Need for implementation of BIM in construction studies}

Modeling and simulations are widely recognized recently with all the affecting parameter of a building still a very difficult to consider during the process of model development to building energy prediction (Elbeltagi et al., 2017). Building modeling tools are often deferred to the later stages of design. In later stages many decisions are already finalized and the opportunities for design improvement are limited, expensive, and harder to implement (Batish\&Akrawal, 2019). Construction projects are becoming more complex and difficult to manage, and as technology develops, more construction professionals are familiarizing themselves with BIM. This has led to a dramatic shift in attention towards the concept of BIM by the construction industry.

BIM is currently the most common denomination for a new way of approaching the design, construction and maintenance of buildings (Abanda\& Byers, 2016). (BIM) Building Information Modeling is growing in pace, in many aspects such as, design, construction, and analysis of facilities during the life cycle. The performance of building energy is largely impacted by the decisions in the early stage and the amount of energy can be reduced by about 30-40\% without the need for any additional cost, if the orientation and shape of building are well designed. Numerous researches have concluded that the simulation of building performance should be implemented in the early stage of building design in order to help designers to achieve high performance buildings (Elbeltagi et al., 2017). However, researchers have found that simulation software tools are 
rarely practiced at the early stage.

This is due to the fact that the main use of building energy simulation tools are to predict the building energy conception and to check for green building rating after building design. Additionally, a significant amount of energy can be saved in later stage of project, if the implementation of BIM is carried out at the early stage of design process (Hemsath, 2013). To sum up, the integration of BIM in construction projects has a great ability to assists architectures in their evaluation to select the best design alternatives at the early stage. In addition, the ability to transfer the information efficiently and quickly designing and simulating the building energy as well as analysis and validation for further process (Li et al., 2019).

\subsection{Need for Prediction Tools to Estimate Energy Consumption}

Due to the fact that and in order to control the demand for energy in buildings and also the need to make buildings more energy efficient, it is critical to predict and optimize building energy consumption. Moreover, AI and Machine learning techniques have been indicated as promising in literature because of superior capability to handle the complex input and output relationship (Raza \&Khosravi, 2015). However, this paper is a part from current Research which is mainly aims to examine the applicability of prediction models techniques in estimating the energy consumption at early stage for mosques. In addition, prediction of the energy consumption of buildings based on machine learning has received increased attention due to its energy-saving potential. Machine learning models have been used in prediction of energy consumption and in the analysis the effects of heating and cooling variables in buildings (Huang et al., 2020). However, the performance of the machine learning model depends on their parameter settings (Ngo, 2019).

Recently, the combinations of prediction models of building energy consumption and the algorithms that used to optimize energy efficiency of buildings in pre-design stage have become a research hotspot. During the design alternatives, the prediction of energy consumption is performed one by one which is very time consuming. Therefore, there is an essential need for accurate and fast calculations method for building energy consumption for early design stage (Alshibani\&Alshamrani, 2017). Moreover, BIM simulation methods can be used in the prediction of energy performance by, developing multiple design alternativesanalyzing these alternatives performance, and create buildings models. Consequently, BIM simulation methods can enhance the extraction process of thermal materials by BIM tools to accelerate the estimation of design alternatives to provide accurate results (Al-Saggaf et al., 2020). It is concluded that the architectural design in not properly determined in the early design stage and the data set is challenging and difficult to achieve as well as the ANN is rarely used for prediction the energy consumption in the early stage if design (Li et al., 2019).

\section{CONCLUSIONS}

Mosque is considered as the most frequently temporally used building compared to other types of buildings (Alsaeah 2013; Alabdullatief et al., 2016).Compare to other buildings types in same region, researches have showed that mosque consume more energy and have higher usage per capita especially for cooling systems (Al-Homoud et al., 2005; Budaiwe et al., 2013; Al-Tamimi\&Qahtan, 2018). Unfortunately they consume a huge amount of energy due to several reasons such: improper and poorly design, lack of studies, and improperly operated. However, the potential for energy conservation is significant.There is a 
clear gab and lack of case studies in terms of enhancing sustainability and reduce energy consumption and how mosques should be designed properly. In this respect, comparing to other buildings types, the searching in terms of enhancing sustainability and reduce energy consumption is considered as a new topic. In addition, only on the last 20 years the researchers have highlighted the issues that confronted the mosques buildings (Alabdullatief\& Omer, 2017).

The aim of this paper is mainly focuses on achieving the following two objectives: (i) investigate the current situation of researches on predicting the energy consumption of mosques, (ii) investigate the issuesconfronting the sustainability environment and energy efficiencycriteria when designing mosques as well as provide recommendations for further future studies. This paper conducted a literature review of related and latest researches of energy consumption trends in regard with mosque buildings and was limited to articles that published from the year of 2000 till 2020. One of the main results shows the lack of information and insufficient number of researches in regard with energy consumption of Mosques. Thisresulted in additional lack of public awareness and government interfere on the problem of energy consumption that unreasonably being wasted.

The limitations of Prediction models that were addressed previously for PMV Prediction of Mean Vote can be extended for studies in future, especially for mosque and with different alternatives and techniques. In addition, there is still a lack of researches in regards with prediction of the energy consumption in mosques. However, many aspects could be investigated in future to enhance the thermal system and decrease the energy consumption by employing different tools and combinations of other models. The prediction of indoor thermal comfort could be largely improved by adopting mixed of (ADP) Air diffusion performance and advanced computational software.

In hot climatic regions, minimizing the energy consumption have become increasingly challenging in many aspects of building industry, due to the ever increasing of the scarcity of natural resources (Alshibani\&Alshamrani, 2017). Therefore, this review study is stresses the need for more studies on optimizing the environment sustainability and reduces the energy consumption in Mosques. In addition, highlights the results of inadequacy of research studies in regard with many aspects of Mosques. Recently, more studies have shown that designing and evaluation at pre-design stage have been approved to have significant contribution in saving huge amount of money and energy conservation. Hence, the results show lack of studies on Mosques at pre-design phase. Additionally, most of researches came up with several strategies and techniques to decrease the energy consumption and apply energy efficiency criteria. Thus, this review indicates that most of previous studies involved retrofitting existed buildings of mosques and limited studied considered their evaluation at the planning stage of mosque designing. This early implementation approved to be significantly for buildings to save a lot of money as well as reduce huge amount of energy consumption. Thus, recently numerous researchers have concluded that combinations of prediction models of building energy consumption and the algorithms that used to optimize energy efficiency of buildings in pre-design stage have become a research hotspot.Prediction of the energy consumption of buildings based on machine learning has received increased attention due to its energy-saving potential.

\subsection{Declaration of Conflict Interests}

The authors declare no potential conflict of interests at all in this paper

\section{REFERENCES}


1. Abanda, F. H., \& Byers, L. (2016). An investigation of the impact of building orientation on energy consumption in a domestic building using emerging BIM (Building Information Modelling). Energy, 97, 517527.

2. Abdou, A. A., Al-Homoud, M. S., \&Budaiwi, I. M. (2005). Mosque energy performance, part I: energy audit and use trends based on the analysis of utility billing data. Engineering Sciences, 16(1).

3. Abdul-Matin, I. (2010). Green deen: What Islam teaches about protecting the planet? Berrett-Koehler Publishers.

4. AlTouma, A., \&Ouahrani, D. (2017, December). Enhanced Thermal Performance of Mosques in Qatar. In IOP Conference Series: Earth and Environmental Science (Vol. 104, No. 1, p. 012012). IOP Publishing.

5. Alabdullatief, A., \& Omer, S. (2017). Sustainable techniques for thermal comfort in buildings designed used by worshipers.

6. Alabdullatief, A., Omer, S., Elabdein, R. Z., \&Alfraidi, S. (2016). Green roof and louvers shading for sustainable mosque buildings in Riyadh, Saudi Arabia.

7. Al-ajmi, F. F. (2010). Thermal comfort in air-conditioned mosques in the dry desert climate. Building and Environment, 45(11), 24072413.

8. Alashaab, A. A. N., \&Alamery, M. S. (2018, December). Investigation And Improvement The Thermal Comfort Of The Air Conditioning mosque At Hot-Dry Climate In Baghdad. In IOP Conference Series: Materials Science and Engineering (Vol. 454, No. 1, p. 012154). IOP Publishing.

9. Al-Homoud, M. S., Abdou, A. A., \&Budaiwi, I. M. (2005). Mosque energy performance, part II: monitoring of energy end use in a hot-humid climate. Engineering Sciences, 16(1).

10. Al-Howaimel, A. (2013). The Ministry of Islamic Affairs is Responsible for 94 Thousand Mosque Buildings in Saudi Arabia Available at: [Alriyadh News Paper].

11. Alsaeah, T. (2013). Energy consumption in Mosques in Saudi Arabia.Aleqtsadia.

12. Al-Saggaf, A., Nasir, H., \&Taha, M. (2020). Quantitative approach for evaluating the building design features impact on cooling energy consumption in hot climates. Energy and Buildings, 211, 109802.

13. Al-Shaalan, A. M., Alohaly, A. H. A., \&Ko, W. (2017). Design strategies for a Big Mosque to reduce electricity consumption in Kingdom of Saudi Arabia. In Proceedings of the 21st World Multi-Conference on Systemics, Cybernetics and Informatics (WMSCI 2017).

14. Alshibani, A., \&Alshamrani, O. S. (2017). ANN/BIM-based model for predicting the energy cost of residential buildings in Saudi Arabia. Journal of Taibah University for Science, 11(6), 13171329.

15. Al-Tamimi, N., \&Qahtan, A. (2018). Assessment of Thermal Behaviour and Energy Consumption of Small Mosques in Hot-arid Climate of Najran City, KSA.

16. Amasyali, K., \& El-Gohary, N. M. (2018). A review of data-driven building energy consumption prediction studies. Renewable and Sustainable Energy Reviews, 81, 11921205.

17. Atmaca, A. B., \&Gedik, G. Z. (2019). Evaluation of mosques in terms of thermal comfort and energy consumption in a temperatehumid climate. Energy and Buildings, 195, 195204.

18. Azmi, N. A., \&Kandar, M. Z. (2019). Factors contributing in the design of environmentally sustainable mosques. Journal of Building Engineering, 23, 2737. 
19. Bakri, A., Zakaria, I. H., Kassim, R., \& Ahmad, A. N. A. (2018). Adoption of the Systematic Facilities Management Approach to the Sustainable Performance of Mosques. International Journal of Technology, 9(8), 15421550.

20. Batish, A., \& Agrawal, A. Building Energy Prediction for Early-Design-Stage Decision Support: A Review of Data-driven Techniques.

21. Budaiwi, I. M., Abdou, A. A., \& Al-Homoud, M. S. (2013, March). Envelope retrofit and air-conditioning operational strategies for reduced energy consumption in mosques in hot climates. In Building Simulation (Vol. 6, No. 1, pp. 33-50). Tsinghua Press.

22. Calis, G., Alt, B., \& Kuru, M. (2015). Thermal Comfort and occupant Satisfaction of a Mosque in a Hot and Humid Climate.In Computing in Civil Engineering 2015 (pp. 139147).

23. DeBoeck, L., Verbeke, S., Audenaert, A., and De Mesmaeker, L. (2015). Improving the energy performance of residential buildings: A literature review.Renewable and Sustainable Energy Reviews, 52, 960975.

24. Deloitte, \& M.E., T. (2015). The Digital Islamic Services Landscape: Uncovering the Digital Islamic Services opportunity for the Middle East and the World. Accessed on [17 Sep. 2017].

25. Elbeltagi, E., Wefki, H., Abdrabou, S., Dawood, M., and Ramzy, A. (2017). Visualized strategy for predicting buildings energy consumption during early design stage using parametric analysis.Journal of BuildingEngineering, 13, 127136.

26. ElShennawy, T., \& Abdallah, L. (2017). An initiative toward transforming mosques in Egypt to be environment-friendly and energy saving. pdf

27. Elshurafa, A. M., Alsubaie, A. M., Alabduljabbar, A. A., \& Al-Hsaien, S. A. (2019). Solar PV on mosque rooftops: Results from a pilot study in Saudi Arabia. Journal of Building Engineering, 25, 100809.

28. Gao, H., Zhang, L., Koch, C., \& Wu, Y. (2019, July). BIM-based real time building energy simulation and optimization in early design stage. In IOP Conference Series: Materials Science and Engineering (Vol. 556, No. 1, p. 012064). IOP Publishing.

29. Hameed, A. N. A. (2011). Thermal Comfort Assessment to Building Envelope: A Case Study for New Mosque Design in Baghdad. International Transaction Journal of Engineering, Management \& Applied Sciences \& Technologies., 2, 249264.

30. Hussin, A., Haw, L. C., Mat, S., Fazlizan, A., \&Salleh, E. (2018). Indoor Thermal Performance of a Retrofitted Air-Conditioned Mosque: Case Study for Penang State Mosque. JURNAL KEJURUTERAAN, 1(3), 3745.

31. Hussin, A., Salleh, E., Chan, H. Y., \& Mat, S. (2015). The reliability of Predicted Mean Vote model predictions in an airconditioned mosque during daily prayer times in Malaysia. Architectural Science Review, 58(1), 6776.

32. Hwang, J. K., Yun, G. Y., Lee, S., Seo, H., \&Santamouris, M. (2020). Using deep learning approaches with variable selection process to predict the energy performance of a heating and cooling system. Renewable Energy, 149, 12271245.

33. Ibrahim, S. H., Baharun, A., Nawi, M. N. M., \&Junaidi, E. (2014). Assessment of thermal comfort in the mosque in Sarawak, Malaysia. International Journal of Energy and Environment, 5(3), 327334.

34. Kamar, H. M., Kamsah, N. B., Ghaleb, F. A., \&Alhamid, M. I. (2019). Enhancement of thermal comfort in a large space building. Alexandria Engineering Journal, 58(1), 4965.

35. Kim, K. H., \& Han, S. H. (2012, April). Sustainable Transparency: Sustainable Design and Performance Verification of an Integrated Tower. In 2012 IEEE Green Technologies Conference (pp. 1-1). IEEE. 
36. Laghmich, N., Khouya, A., Romani, Z., \&Draoui, A. (2018, December). The reduction of energy requirement by adapting the mosques building envelope for the six climatic zones of Morocco.In AIP Conference Proceedings (Vol. 2056, No. 1, p. 020016).AIP Publishing LLC.

37. Li, Z., Dai, J., Chen, H., \& Lin, B. (2019, August). An ANN-based fast building energy consumption prediction method for complex architectural form at the early design stage. In Building Simulation (Vol. 12, No. 4, pp. 665-681).Tsinghua University Press.

38. MIADG. (2017). Statistical Book for the year 2016.Ministry of Islamic Affairs, Dawah and Guidance. Accessed on [06 Dec. 2017], Available through:www.moia.gov.sa

39. Mokhtar, A. (2015). Comparison of Energy Efficiency Strategies for Mosques in the United Arab Emirates.In AEI 2015 (pp. 4353 ).

40. MATARNEH, MOHAMMAD ESSA. "Improvement of abrasive and edge cutting machining efficiency through theoretical analysis of physical conditions." Int. J. Mech. Prod. Eng. Res. Dev 8.2 (2018): 249262.

41. Mushtaha, E., \&Helmy, O. (2017). Impact of building forms on thermal performance and thermal comfort conditions in religious buildings in hot climates: a case study in Sharjah city. International Journal of Sustainable Energy, 36(10), 926944.

42. Ngo, N. T. (2019). Early predicting cooling loads for energy-efficient design in office buildings by machine learning. Energy and Buildings, 182, 264273.

43. Nordin, N. I., \&Misni, A. (2018, February). Evaluating the interior thermal performance of mosques in the tropical environment. In IOP Conference Series: Earth and Environmental Science (Vol. 117, No. 1, p. 012014). IOP Publishing.

44. Østergård, T., Jensen, R. L., \&Maagaard, S. E. (2016). Building simulations supporting decision making in early design-A review. Renewable and Sustainable Energy Reviews, 61, 187201.

45. Patil, Bhagyashree, and MarutiLimkar. "Machine to Machine Communication Based Electricity Monitoring and Billing System." International Journal of Electrical and Electronics Engineering Research (IJEEER) ISSN (P) (2016).

46. Purup, P. B., \& Petersen, S. (2020). Requirement analysis for building performance simulation tools conformed to fit design practice. Automation in Construction, 116, 103226.

47. Raza, M. Q., \&Khosravi, A. (2015). A review on artificial intelligence based load demand forecasting techniques for smart grid and buildings. Renewable and Sustainable Energy Reviews, 50, 13521372.

48. Samiuddin, S., \&Budaiwi, I. M. (2018). Assessment of thermal comfort in high occupancy spaces with relevance to air distribution schemes: A case study of mosques. Building Services Engineering Research and Technology, 39(5), 572589.

49. LAKSHMAN, R., and A. Ramesh."A System Dynamic Analysis of Energy Consumption and CO2 Emission of Indian Iron and Steel Industries." International Journal of Mechanical Engineering 3.4 (2014): 4960.

50. Sezer, F. S., \&Kaymaz, E. (2016). The User's Perception of Indoor Comfort Conditions in Historical Mosques: The Case of Bursa, Turkey. International Journal of Humanities and Social Science, 6(9), 4354.

51. Shohan, A. A. A. (2015). Thermal Comfort and Energy Demand of Small and Large Mosque Buildings in Saudi Arabia.

52. Stundon, D., Spillane, J. P., Lim, J. P., Tansey, P., \& Tracey, M. (2015). Building information modelling energy performance assessment on domestic dwellings: a comparative study.

53. Tran, D. H., Luong, D. L., \& Chou, J. S. (2020). Nature-inspired metaheuristic ensemble model for forecasting energy consumption 
in residential buildings. Energy, 191, 116552.

54. VERMA, SACHIN, and SUDHIR Y. KUMAR."A review on thermodynamics analysis and waste energy utilization in cement industry." International Journal of Mechanical and Production Engineering Research and Development 7 (2017): 203212.

55. Wang, H., \&Zhai, Z. J. (2016). Advances in building simulation and computational techniques: A review between 1987 and 2014. Energy and Buildings, 128,319335. 

www.tiprc.org 